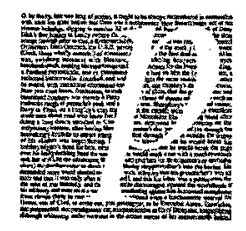

\title{
Borges, ahijado de Chesterton
}

\author{
Kathleen Haney \\ University of Houston-Downtown
}

$\mathrm{J}$ orge Luis Borges enjoys a well-earned reputation as an innovator in literature and the arts. No one will argue that Latin American letters without Borges are imaginable. The current fashion, popular and just, involves uncovering indigious influences in Latin American works of magical realism. We can train ourselves to see crevices through which a dominant culture can become eroded by tributaries of streams of otherness. A whole culture then becomes a baroque artifact which features folds, passages away from a monolithic structure into labyrinths of textures and spaces so that a culture may be better understood on the model of a cave than a tall building. The art of the critic relies on deconstruction only to the extent, then, that such activity invites her to the entrance of the cave so that the real exploration can begin. After all, truly the critic is no more drawing a blueprint of a literary construction than the artist was following one. The map of the spelunker includes crystalline streams passing from darkness to light and back again, caverns of richness which relinquish their treasure in dim, opportunistic light, confused passages which lead nowhere to the end of space and the beginnings of panic, especially if the cavern is that abyss, Borges.

According to a critic, Borges "forges a new idiom: an audacious cultural hybrid that can transfer the Crucifixion to an Argentine ranch, fuse Zeno's paradoxes with memo- 
ries of the outlying neighborhoods of Buenos Aires, or incarnate God in gauchos and guapos (hoodlums)" (Aizenberg 1990, 4). In this reading, Borges' writings train us to see the crevices through which a dominant culture can become eroded by tributaries of streams of otherness. Ana Maria Barrenechea writes of the resulting work as an effort to fuse "universal motifs with life on the periphery in the far-off republics of the south" (in Aizenberg 1990, 18).

Borges himself acknowledges additional influences, however. One of these is the unlikely G. K. Chesterton, a.Christian apologist, a convert to Roman Catholicism, an Englishman, of a race of colonizers. In this piece, I shall pursue an unlikely otherness in Borges' work, the other, Chesterton, from a phenomenological perspective. Understanding real otherness requires empathy. A pairing process that involves a sharing of meanings is the necessary condition for empathy. Recognizing an other as an alter ego must precede the possibility of knowing the other individual as he is for himself. The pair, Borges-Chesterton, includes overlapping intentions, held in common, according to Borges. An examination of the writer and his self-selected precursor, as a single, unified-paired meaning may permit another glimpse at the subsequent Borges.

Borges taught his critics "the first principle of poetic influence-that each writer creates his own precursors" (Aizenberg 1990, 2). We must immediately acknowledge that the creation of precursors is a mode of discovery. A precursor writes before and leaves a legacy of fallow ground for receiving the seeds that it can nourish. Borges famously considers Kafka as a precursor in a disparate line that includes Zeno, Leon Bloy, Soren Kierkegaard, Robert Browning, and Lord Dunsany (Borges 1964a, 106-108). Borges claims a literary heritage from such other writers as $\mathrm{Han} \mathrm{Yu}$, Spinoza, the author of the Book of Job, and Nathaniel Hawthorne, as well. Yet, these influences do not result in the re-readings of the earlier writers. Like land and other holdings though, a precursor is changed by the intentions of the heirs. Borges does not miss the irregularity of the groupings he compiles. Indeed, he immediately recognizes a principle of literary interpretation in the liberty he has taken. "If I am not mistaken, the heterogeneous selections I have mentioned resemble Kafka's work: if I am not mistaken, not all of them resemble each other, and this fact is the significant one. Kafka's idiosyncrasy, in greater or lesser degree, is present in each of these writings, but if Kafka had not written we would not perceive it; that is to say, it would not exist" (Borges 1981, 243).

According to other Borgesian principles having to do with the functions of the critics and the reader, we may infer that reading creates precursors and alternate interpretations for other writers, as well. Indeed, Borges introduced us to the activity of rereading genealogically, in pursuit of family resemblances. Borges believes that literature lives in such continual re-construction. His own fiction provides the requisite deconstructive moment, a hesitation, a doubt, and resolves it in a non-obvious fashion that invites a somewhat different world. This possibility is one of debts that Borges claims he owes to Chesterton.

Following Borges' interpretative practice leads to a view on his work through the eyes which have found the British defender and popularizer of Christianity and Roman 
Catholicism, Gilbert Keith Chesterton, to be oddly enough, Borges' own predecessor. Borges' Chesterton is a member of the tradition of the fantastic, especially in the contemporary form of magical realism. Borges was dissatisfied with the positivism of Comte that dominated Latin American intellectual circles. Borges' Chesterton is a master at problematizing reality, "We have all forgotten what we really are. All that we call common sense and rationality and practicality and positivism only means that for certain dead levels of our life we forget that we have forgotten. All that we call spirit and art and ecstasy only means that for one awful instant we remember that we forgot" (Chesterton 1959,54). The mystery of that vague sense which is not easily disposed of invites the challenge of possibility. To those who seek truth that which can be known with certainty diminishes in significance.

Borges says of himself that he remains in the Cave that Plato described, but this Cave is enlightened and freed of danger by his inexorable conviction that all humans are necessarily cave dwellers. Borges, unlike the ordinary modern, knows that he looks at shadows, but also unlike the moderns, he has no illusions about an "objective" truth seen as without perspective. Plato's cave is the many caves into which we are born and initially enculturated, to which the sympathetic critic of Borges returns; it is the cave he has never left. Borges' cave is in Argentina, but its furnishings boast eclectic origins. Into this cave, no light can shine which can relieve all the darkness; nevertheless, such a cave is the rightful home of the human. Indeed, his certainty concerning the limits of human sight is one of Borges' favorite themes. The intellect can only appreciate that the space of human light remains surrounded by blackness that the horizon that we can grasp is itself situated against a clammy background, which we can grope. Through our gropings, we can domesticate a darkness that is always larger than we can fathom.

Dreams and song make the world bearable, habitable; they make the dark places bright. Blindness of the soul - which is the one that counts - is the natural state of man, and woe to him who does not see in time that we live surrounded by shadows! The poet, the hacedor, makes this discovery one day and descends into the shadows unafraid, illumined by his creative consciousness.... Borges and Homer know, then, that this is where everything begins, in the bold loving acceptance of life and in the drive that impels them to people their darkness with voices. $(1964 \mathrm{~b}, 13)$

When we explore the cavern of Borges' work with Chesterton, we lose the feel of the abstractions that provide some kind of map. The blind and the lost and those in need of a laugh often search Chesterton's cave to discover the Man/God re-born there. Borges' labyrinth follows the channels that Chesterton explored as he evoked the supernatural in the natural. Adventure and danger return if the cave can be explored. As Borges recognizes, Chesterton is alive to both the perils and the wealth of human experience. Chesterton appropriated the nominalism' that has long since carried the day to turn the little, the details, the incarnate to the universals that make intelligibility possible by providing means to speak at all. Chesterton's insight is that the actual, although necessarily possible, need not be as it is. Indeed, this actual need not be, but remarkably, is. Borges celebrates Chesterton as pathfinder and spelunker. "Chesterton," he writes "is a man who wants to regain childhood" (1964a, 81). Despite Borges' extraor- 
dinary sophistication and erudition, he likewise embraces the joyful playfulness that mocks the clocks and schedules and the ignorance of those who think they know the solution to the enigma of human existence.

Borges captures an aspect of Chesterton's attempt to grasp the spirit of childhood in his contrast between Chesterton and Croce on the question of allegories. For the latter, Borges explains, allegories are "a kind of writing or cryptography" (1964a, 155), "an esthetic sport" $(1981,219)$, while for Chesterton allegories are not equations, solvable with proper formulas. Chesterton denies that the genre is censurable; allegories are metaphors, rich and inexhaustible. He reasons that reality is interminably rich and that the language of men cannot exhaust that vertiginous treasure. Borges quotes his "beloved Chesterton" (Zamora 1995): ${ }^{2}$

Man knows that there are in the soul tints more bewildering, more numberless, and more nameless than the colours of an autumn forest ... Yet he seriously believes that these things can every one of them, in all their tones and semi-tones, in all their blends and unions, be accurately represented by an arbitrary system of grunts and squeals. He believes that an ordinary civilized stockbroker can really produce out of his own inside noises which denote all the mysteries of memory and all the agonies of desire. (1964a, 155)

Borges' Chesterton sees that various languages can somehow correspond to ungraspable reality, and among these are allegories and fables since their meanings are necessarily underdetermined $(1981,219)$. Yet, a story has a point, "even if it is a story in the sense of a lie" (Chesterton 1955, 175). Borges criticized one of his "mentors," Nathaniel Hawthorne, for violating this disciplined application of the interpretative principle of generosity when he appends "the moral."' But, there can be no "moral," as if all subjects will get the same point, as if each will make the same meaning, always the one privileged meaning. Chesterton has a strange little companion piece to Hawthorne's "Homesick at Home," the story of a man who suddenly starts in non-recognition of the home of his birth, childhood, and manhood. His home is not his own until he journeys around the world to return as a prodigal son. He does not escape into loneliness; loneliness follows on the heels of familiarization in order to overtake him and thrust him out of the unrecognizable familiar in order to allow him to see his home and his kin again. Space as a material dimension may be irrelevant to location or space is at best a proto-constitution of psychological "lived" time. Coming home is the point of the story, but where is home? Or, when?

In his analysis of the symbology of Christmas, Chesterton emphasized that the famed manger was in a stable in a cave. Baby Jesus, impossible to visualize without his mother, enacts the first act of the divine drama

(...) not only on no stage set up above the sight-seer, but on a dark and curtained stage sunken out of sight; and this is an idea very difficult to express in most modes of artistic expression. It is the idea of simultaneous happenings on different levels of life. Something like it may have been attempted in the more archaic and decorative medieval art. But the more the artists learned of realism and perspective, the less they could 
depict at once the angels in the heavens and the shepherds on the hills, and the glory that was in the darkness that was under the hills. $(1955,175)$

Note that the failure of portrayal results from psychological realism (a genre Borges too held in contempt) under the guise of perspective and the hypothesis of naturalism. The richer logic of possibility invites allegories and analogies to evoke strata of life.

Borges' Chesterton's topic is the logic of the imagination. This logic suspends natural and spatial categories as it approaches the transcendentals, but this logic has its lawfulness as well as its playfulness. The precursor, Chesterton, allows us to see that he and Borges shudder together in awe before reason. Chesterton exercises what I call transcendental logic, the logic of possibility, especially in his detective stories. Borges heralds Chesterton as the Master of the Detective Genre for this reason. Chesterton's Father Brown possesses a keen sense of the mysterious, which he seeks with a catholic openness and greets with a joie de vivre. False beards and unlikely coincidences cannot detract from the logic of his solutions. Edgar Allan Poe may no longer claim the title, Master of the Obvious, for "The Purloined Letter." The hidden secured in the obvious, the theme of all great detective stories, provides an experience of an emotional expression of spatial juxtaposition against a temporal horizon, which, nonetheless, makes sense. Borges after Chesterton does one better. "Tom Castro, The Implausible Impostor" exploits the theme in an impersonation so unlikely that the grieving mother and anxious creditors accept the candidate since he is fully different from the lost and we all know what fifteen years can do.

Chesterton must be a master of the fantastic, as well. His logic of isomorphic spheres makes his theoretical control of imaginative possibility impeccable. Borges observes that "Chesterton always performs the tour de force of proposing a supernatural explanation and then replacing it, losing nothing, with another one from this world" (1981, 71-73). Chesterton's stories satisfy us because their naturalistic conclusions are not ineluctable. Without giving anything away from the supernatural hypothesis, Chesterton allows both possibilities to maintain. Borges explains that

... magic is not the contradiction of the law of cause and effect but its crown, or nightmare.... All of the laws of nature as well as those of imagination govern it. To the superstitious mind, there is a necessary link not only between a gunshot and a corpse but between a corpse and a tortured image, or the prophetic smashing of a mirror, or spilled salt, or thirteen people ominously seated at the same table. $(1981,37-38)$

Chesterton's own position is stronger still. "It is no argument for unalterable law... that we count on the ordinary course of things. We do not count on it; we bet on it. We risk the remote possibility of a miracle as we do that of a poisoned pancake or a world-destroying comet. We leave it out of account, not because it is a miracle, and therefore an impossibility, but because it is a miracle, and therefore an exception" $(1959,55)$. Chesterton's literary universe expands to include magical exceptions, as long as they are not impossibilities such as Cinderella-being older than her elder stepsisters or three magic beans and two magic beans making six. Chesterton's mirrors reflect what the vastness of what is not present, though it might be. Borges writes, 
Every episode in a painstaking piece of fiction prefigures something still to come. Thus, in one of Chesterton's phantasmagorias, a man suddenly shoves a stranger out of the road to save him from an oncoming motorcar, and this necessary but alarming violence foreshadows the first man's later act of declaring the other man insane so that he may not be hanged for a murder... Between the two, there is a long repercussion. I have pointed out two chains of cause and effect: the natural, which is the incessant result of endless, uncontrollable processes; and the magic, in which-clear and defined-every detail is an omen and a cause. In the novel, I think that the only possible integrity lies in the second. $(1981,38)$

Borges uses Chesterton's detective novels to formulate the following critical code: "...the fulfilling solution must be both necessary and wonderful. The first establishes that the mystery should be a determined mystery, fit for only one solution. The second requires that the reader marvel over that solution, without resorting to the supernatural, of course, whose handiwork in this genre of fiction is a weakness and a felony" (1981, 87-91). The supernatural solution is not impossible, however, and Chesterton's command of logic results in plots that range over possibilities so that their conclusions are foregrounded as actual, although they may have been otherwise. Such conclusions fit perfectly without thereby exhausing the possibilities of perfect fit. The glass slipper may only fit Cinderella's foot, but her foot can also put on more comfortable shoes.

No less than logic, language is a determinant, even if it does not overly determine. Borges recommends Chesterton's "fine verbal economy" in his titles $(1981,90)$. Borges writes that Chesterton's titles present concrete images which the author takes as debts to be fulfilled since he knows he has limited his possibilities by naming them. "We know that in Les palais nomads there are no nomadic palaces, we know that "The Oracle of the Dog' will not lack a dog and an oracle, or a concrete, oracular dog" (1981, 90 ). The thematic presence of the real as actualized possibility opposed to undetermined possibility is for Borges more than a concession to the time-worn metaphysics of realism. Rather, bodily being is a kind of mystery itself, implacable, inevitable, and inexplicable. Its revelation is one of the genuine gifts of twentieth century phenomenological philosophy. Yet, the simply real and the really concrete are present already in Chesterton, that old traditionalist. We hear that poignant note in Borges' confession, "The world, alas, is real; I, alas, am Borges" (1981, 190).

When Chesterton guides the reading, Borges is more down to earth. On the heels of his precursor, Chesterton, Borges leads into the mysterious and wonderful that surrounds us once we desist in our frenzied efforts to naturalize all of existence. Language can disclose the dimensions of experience by pointing to an actual fiction governed by logical lawfulness. Logic, after all, concerns entities about which existence claims are irrelevant. Logical entities are both ideal and real or neither, as phenomenologists say. Borges, after Chesterton, follows in a tradition of Christian Humanism, in the cult of the civilized person as the rationalist, although Borges lacks the religious motivation. This twist seems to conflict with the iconoclastic Borges, student and master of the fantastic, unless we see that the setting for magical realism is a world transformed by the intuition of wonder at its actualities as well for its possibilities. Even the fantastic, if it 
is to be believable is limited by a stringent rationality, which never violates the law against incompossibilities.

Chesterton's version of the logic that operates in "elfland" and in all true fairy tales and fictions points to a realm of necessary relations which transcend ontological status. Likewise although the fantastic may suspend logic, it never violates logic. Often the fantastic may depend on "...the reader's initial-i.e. prior to the hesitation created by the narrative--rejection of the supernatural. That rejection results from the opposition between the real and the unreal, which constitutes the basis from which those texts operate in order to carry out their aims. For that opposition to be successful, the story must be told in a realistic manner..." (Rodriguez-Luis 1991, 1). Unless the conventions of the laws of psychological realism are in play, impossible elements cannot come to the fore, so that the desired effect of making us wonder about reality does not come about.

The reader's doubt is provoked only if the story pretends to be, and is understood by the reader as being realistic, except, of course, for that element which appears to be supernatural. In other words, the reader has to question the nature of events and not, instead, 'that of the very text which describes.' The latter is precisely what happens in allegorical texts, which constantly point beyond what is being recounted, apparently following realistic conventions, and suggest that the text contains a half-hidden meaning for which the entire narrative is but a vehicle.... Thus, in an allegorical short story or novel, the supernatural occurs not in order to make us question our faith in reality, but as the vehicle for carrying the meaning of the story. (Rodriguez-Luis 1991, 6)

Stories of the fantastic seem initially to be about this thing or that, belittling the opposition between the real and the unreal, which constitutes the basis from which those texts operate in order to carry out their aims. The reader's experience of uncanny feelings when confronting the fantastic results from her appreciation that the supernatural may be quite real, even natural. An allegory or a detective story can evoke the supernatural, at least as a spiritual dimension. The necessity of generating doubt about the reality of the world we take for granted is intrinsic to the success of a fantasy, as well as for understanding the fantastic, and cannot be overestimated, even if

...some narratives do not actually rely on it for their effect. Although the majority of readers do not believe that the laws of nature can be subverted, they enter, in the successful fantastic story, into a game with its author devised by the latter to make us suspend momentarily that belief in the impossibility of the supernatural to which we all so firmly subscribe in real life; to hesitate, in other words, between rejecting and accepting the possibility of the impossible. In the case of some exceptional texts, that uncertainty will transform itself into a doubt-a feeling more encompassing and of more lasting effects than the hesitation-that accompanies us after the narrative has ended. (Rodriguez-Luis 1991, 1)

Chesterton is clear that the doubt that liberates and awakens is the doubt that the supernatural really is impossible. His fiction evokes experience of supernatural meaning, but does not rest with it. 
Meanings, of course, need have no particular metaphysical substance or ontological status necessarily associated with them. The meant can be meant as counter-factual or imaginative or emotional as well as real and so forth. Meanings, insofar as they are meant, are meant in a mode of possibility (even the impossible is a species of possible meaning). Possibility thus functions as the common denominator of all experience. This claim need not be empty, however. For instance, even if all meanings must be possible as meanings, they may not all be compossible. Dallas need not be north of Houston. Yet, if Dallas is north of Houston, Dallas cannot be south of Houston. Again, we hear Borges' lament, "The world, alas, is real; I, alas, am Borges."

The pairing that permits Borges' association with Chesterton moves from the Argentine's private experience to critical interpretation through the intermediary of meaning-making. The meaning of the pair, Borges/Chesterton, results from the overlaying of the meaning, precursor by the heir who claims the legacy of delicious, quirky humor and vast, real possibilities. Not only space and time as Kant held, but other formal conditions accrue to possibility as the possibility of such and such a possibility. Actuality precedes possibility to function as its necessary condition. Chesterton whole-heartedly embraces the actual (even as fictive actuality) as the necessary condition for the possible, but reminds us that the actual need not be as it is or even be, at all. This remarkable insight, obvious in his stories, sets a logic for the fantastic. Imagination, in its various intellectual musings, establishes the limits to possibility. The unimaginable, ipso facto, cannot be possible. What remains, in all its vastness, is the world that Chesterton and Borges share.

\section{Notes}

1 "Borges's considerable Anglophilia makes him go further, and ... suggest that our [English] Nominalism is ethical rather than philosophical, that it is part and parcel of the high respect we feel for individuals." This observation surely describes Chesterton's position (Sturrock 1977).

${ }^{2}$ As she well knows, Professor Zamora's keen literary sense is the inspiration behind this paper.

\section{Works cited}

Aizenberg, Edna (ed). 1990. Borges and His Successors. Columbia and London: University of Missouri.

Barrenechea, Ana Maria. 1990 "On the Diverse (South American) Intonation of Some (Universal) Metaphors," in Borges and His Successors.

Borges, Jorge Luis. 1964a. Other Inquisitions. Tr Ruth L.C. Simms. Austin: University of Texas Press.

- 1964b. Dreamtigers. Trans Mildred Boyer and Harold Morland. Austin: University of Texas Press. (From the introduction by Miguel Enguidanos, p. 51).

-. 1981. Borges A Reader. Emir Rodriguez Monegal and Alastair Reid (eds.). New York: E.P. Dutton. 
G.K. Chesterton. 1955. The Everlasting Man. Garden City, New York: Image Books. 1959 Orthodoxy. Garden City, New York: Image Books.

Rodriguez-Luis, Julio. 1991. The Contemporary Praxis of the Fantastic Borges and Cortazar. New York \& London: Garland Publishing, Inc.

Sturrock, John. 1977. Paper Tigers. Oxford: Clarendon Press.

Zamora, Lois Parkinson. 1995. "Magical Romance/Magical Realism: Ghosts in U.S. and Latin American Fiction," in Magical Realism. Lois Parkinson Zamora and Wendy B. Faris (eds). Durham: Duke University Press. 